\title{
Sequential His bundle and left ventricular pacing for cardiac resynchronization
}

Citation for published version (APA):

Deshmukh, A., Sattur, S., Bechtol, T., Heckman, L. I. B., Prinzen, F. W., \& Deshmukh, P. (2020).

Sequential His bundle and left ventricular pacing for cardiac resynchronization. Journal of Cardiovascular Electrophysiology, 31(9), 2448-2454. https://doi.org/10.1111/jce.14674

Document status and date:

Published: 01/09/2020

DOI:

10.1111/jce. 14674

Document Version:

Publisher's PDF, also known as Version of record

Document license:

Taverne

Please check the document version of this publication:

- A submitted manuscript is the version of the article upon submission and before peer-review. There can be important differences between the submitted version and the official published version of record.

People interested in the research are advised to contact the author for the final version of the publication, or visit the DOI to the publisher's website.

- The final author version and the galley proof are versions of the publication after peer review.

- The final published version features the final layout of the paper including the volume, issue and page numbers.

Link to publication

\footnotetext{
General rights rights.

- You may freely distribute the URL identifying the publication in the public portal. please follow below link for the End User Agreement:

www.umlib.nl/taverne-license

Take down policy

If you believe that this document breaches copyright please contact us at:

repository@maastrichtuniversity.nl

providing details and we will investigate your claim.
}

Copyright and moral rights for the publications made accessible in the public portal are retained by the authors and/or other copyright owners and it is a condition of accessing publications that users recognise and abide by the legal requirements associated with these

- Users may download and print one copy of any publication from the public portal for the purpose of private study or research.

- You may not further distribute the material or use it for any profit-making activity or commercial gain

If the publication is distributed under the terms of Article $25 \mathrm{fa}$ of the Dutch Copyright Act, indicated by the "Taverne" license above, 


\section{Sequential His bundle and left ventricular pacing for cardiac resynchronization}

\author{
Amrish Deshmukh $\mathrm{MD}^{1}$ \\ Luuk I. B. Heckman MD ${ }^{4}$
}

${ }^{1}$ Department of Internal Medicine, Division of Cardiovascular Medicine, Samuel and Jean Frankel Cardiovascular Center, University of Michigan, Ann Arbor, Michigan, USA

${ }^{2}$ Department of Internal Medicine, Division of Cardiology, Arrhythmia Center, Robert Packer Hospital, Sayre, Pennsylvania, USA

${ }^{3}$ Department of Field CRM, Abbott,

Williamsport, Pennsylvania, USA

${ }^{4}$ Cardiovascular Research Institute

Maastricht, Maastricht, The Netherlands

\section{Correspondence}

Pramod Deshmukh, MD, Arrhythmia Center, Robert Packer Hospital, 1 Guthrie Sq, Sayre, PA 18840, USA.

Email: Seck_pat@guthrie.com

Disclosures: Tim Bechtol is employed by Abbott.

\begin{abstract}
Introduction: Fusion of left ventricular pacing with intrinsic conduction provides superior resynchronization compared to biventricular pacing. His bundle pacing (HBP) preserves intrinsic conduction and allows for constant fusion with left ventricular pacing. This study evaluated sequential His bundle and left ventricular pacing for cardiac resynchronization therapy (CRT).

Methods: In patients referred for CRT, sequential His bundle and left ventricular pacing was performed when HBP did not correct the QRS. At implant, QRS duration and area were compared between biventricular pacing and His bundle and left ventricular pacing. Devices were programmed for His and left ventricular pacing. Functional status and echocardiography were evaluated in follow up.

Results: Twenty-one patients, seven female, $70.7 \pm 9.9$ years, $57 \%$ with nonischemic cardiomyopathy were included. Baseline QRS duration was $170 \pm 21 \mathrm{~ms}$ and was $157 \pm 16 \mathrm{~ms}$ with HBP. Biventricular pacing resulted in a QRS duration of $141 \pm 15 \mathrm{~ms}$ and decreased to $110 \pm 14 \mathrm{~ms}$ with His bundle and left ventricular pacing $(p<.0005)$. His bundle and left ventricular pacing resulted in a smaller paced QRS area $(38.5 \pm 22.6 \mu \mathrm{Vs})$ compared to biventricular pacing $(67.5 \pm 24.0 \mu \mathrm{Vs})$ and baseline $(78.1 \pm 28.1 \mu \mathrm{Vs} ; p<.0005)$. Left ventricular ejection fraction increased from $27.6 \pm 6.4 \%$ to $41.1 \pm 12.5$ (at 25 mean months, $p=.001$ ) and functional class improved from $3.1 \pm 0.5$ to $2.1 \pm 0.8$ (at mean 32 months, $p<.001$ ).

Conclusions: Sequential His bundle and left ventricular pacing results in superior electrical synchrony in patients with indication for CRT when HBP does not correct the QRS and resulted in promising clinical and echocardiographic response rates.

\section{KEYWORDS}

cardiac resynchronization, His bundle pacing, QRS area
\end{abstract}

\section{1 | INTRODUCTION}

Electromechanical dyssynchrony with prolonged QRS is present in approximately one-third of patients with heart failure with reduced ejection fraction (HFrEF) and is associated with increased morbidity and mortality. ${ }^{1-3}$ While cardiac resynchronization therapy (CRT) with left ventricular pacing via a lead in the coronary sinus (CS) can improve quality of life and mortality, up to $30 \%$ of patients do not have a symptomatic or structural response. ${ }^{4}$ As a result, alternatives to achieving more effective ventricular resynchronization such as multisite and endocardial left ventricular pacing have been investigated. ${ }^{5-7}$ 
His bundle pacing (HBP) is also a feasible alternative for cardiac resynchronization through restoration of physiologic activation by the His-Purkinje system. ${ }^{8-15}$ However, in $10 \%-40 \%$ of patients, selective HBP will not successfully induce resynchronization or may require prohibitively high capture thresholds to do so. ${ }^{8-15}$ In addition, in long term follow up, the capture thresholds required to induce resynchronization may rise significantly. ${ }^{10,12}$

In patients with prolonged QRS in whom HBP does not induce resynchronization, sequential $\mathrm{HBP}$ and left ventricular pacing allows for constant fusion of the intrinsic His-Purkinje activation and ventricular paced activation over the range of atrioventricular intervals. This approach therefore allows for optimal atrioventricular timing and may result in superior intraventricular synchrony when compared with standard biventricular pacing. This theoretical advantage is supported by data from acute hemodynamic studies in humans and animal models in which the fusion of intrinsic or paced His-Purkinje activation with left ventricular pacing via a CS lead resulted in superior hemodynamics when compared to traditional biventricular pacing. ${ }^{16,17}$ We therefore sought to investigate the outcomes of sequential HBP and left ventricular pacing in patients with HFrEF and indication for CRT when HBP alone did not normalize the QRS.

\section{2 | METHODS}

\subsection{Patient selection}

In this single center retrospective study, patients who had sequential $\mathrm{HBP}$ and left ventricular pacing were identified. Patients were identified through review of all patients with follow-up within 5 years with a Select Secure pacing lead (Model 3830, Medtronic, Inc., Minneapolis, $M N)$. At our institution, HBP is offered routinely as a means of CRT and the analyzed cohort consist of patients in whom selective HBP did not induce a QRS duration less than 130 ms who subsequently had a CS lead placed. The patients included are those who provided informed consent which included the use of HBP as an alternative method for CRT and the additional use of a CS lead if this approached failed. These patients had left bundle branch block (LBBB) with QRS $>120 \mathrm{~ms}$ or non-LBBB with QRS > $150 \mathrm{~ms}$, HFrEF with left ventricular ejection fraction (LVEF) $\leq 35 \%$, and New York Heart Association (NYHA) class II to IV symptoms. LBBB was defined by American Heart Association consensus statement criteria. ${ }^{18}$ Data collection and analysis was approved by the Institutional Review Board.

\section{2 | Procedural details}

HBP was performed as previously reported by localization of the His bundle with a femoral mapping catheter and subsequent delivery of a SelectSecure pacing lead to the location (Model 3830, Medtronic, Inc.) via a fixed sheath (C315HIS; Medtronic, Inc.). ${ }^{19}$ Selective HBP was confirmed by: a pace-ventricular interval equal to the Hisventricular interval, a single discrete local ventricular electrogram in the His bundle lead, concordance of the paced and native QRS and $\mathrm{T}$ waves, and identification of a single capture threshold. ${ }^{20}$ After confirming that selective HBP did not normalize the QRS (i.e., HBP QRS remained $>130 \mathrm{~ms}$ ), patients underwent placement of a CS lead. HBP was abandoned if a threshold output less than $3.0 \mathrm{~V}$ at $1.5 \mathrm{~ms}$ could not be obtained. All patients also received a right ventricular implantable cardioverter defibrillator lead. In patients with high His bundle implant thresholds, initial device programming was chosen to either allow for high output or a lower than usual safety margin. In general, a high output was allowed in those patients felt to be more ill and in whom the benefit of resynchronization would be greatest.

In patients with persistent atrial fibrillation (AF), atrioventricular nodal ablation was performed and no atrial lead was placed. In these patients, the His bundle lead was placed into the atrial port of the device and, in general, a DF-4 device was used (Figure S1). For patients without persistent AF, a DF-1 device was used. In these patients, an atrial lead was placed. The left ventricular port was split with the use of an adapter (Oscor Inc., Palm Harbor, FL) such that the distal pole of the left ventricular port was used for unipolar His pacing and the proximal pole was used for unipolar right ventricular lead pacing. The CS lead was connected to the right ventricular pacing port and used to sense ventricular arrythmias (Figure S2). At the time of implant, the devices were temporarily programmed to biventricular pacing with the right ventricular to CS lead offset programmed to minimize the QRS duration. The devices were then programmed to perform sequential His bundle and left ventricular pacing where the His to CS lead offset was programmed to minimize the QRS duration.

\subsection{Follow up and analyses}

At implant, 12 lead surface electrocardiograms were obtained at baseline, with $\mathrm{HBP}$, with biventricular pacing, and with sequential His bundle and left ventricular pacing. These 12 lead electrocardiograms were assessed for QRS duration. The electrocardiograms were recorded digitally at a paper speed of $25 \mathrm{~mm} / \mathrm{s}$ and a frequency of $250 \mathrm{~Hz}$ and stored as PDF files (GE Healthcare, Waukesha, WI). In a subset of patients with adequate quality electrocardiograms, vectorcardiograms were constructed and used to calculate a vectorcardiographic QRS area for each pacing mode as previously described. ${ }^{21}$

After implant, patients were followed in device clinic at 1, 3, 6 months, and yearly along with remote monitoring every 3 months. At initial programming His capture thresholds were defined at 0.6-1.0 ms pulse width. Capture thresholds were first defined at $0.6 \mathrm{~ms}$ pulse width and if His capture thresholds exceeded $2 \mathrm{~V}$, pulse width was increased up to $1.5 \mathrm{~ms}$. Echocardiograms were performed at baseline and as clinically indicated in follow-up and were interpreted with respect to LVEF and left ventricular end diastolic volume (LVEDV). Structural response to CRT was defined as improvement in LVEF by $\geq 10 \%$ or reduction in LVEDV by $\geq 10 \%$. Symptomatic response to CRT was defined as improvement in NYHA class by 1 with no heart failure hospitalization or death in follow up. Continuous 
variables are presented as mean $\pm S D$. Comparisons of QRS duration and QRS area between pacing modes were made using Kruskal-Wallis and comparisons of LVEF and LVEDV were made using paired Wilcoxon signed rank tests.

\section{3 | RESULTS}

A total of 21 patients underwent successful placement of devices programmed for sequential HBP and left ventricular pacing between November 2010 and May 2018. Patients were clinically followed for an average duration of 32 months after implant before data analysis (range: 35-2918, median: 316).

\section{1 | Baseline characteristics}

The clinical characteristics of the study population are summarized in Table 1. Mean age at implant was $70.7 \pm 9.9$ years and seven patients were female. Baseline LVEF was $27.6 \pm 6.4 \%$ and a majority of patients (19 of 21 ) had NYHA class III to IV symptoms. In 13 patients, atrioventricular nodal ablation was performed due to longstanding persistent AF. The baseline characteristics of this group were similar to the overall cohort other than with regard to AF (Table 1). Characteristics of the device configurations used and programming are listed in Tables S1 and S2. No acute complications occurred including lead dislodgement, pneumothorax, cardiac perforation, pocket hematoma, or death.

\subsection{Acute electrophysiologic parameters}

Baseline H-V interval was $56.8 \pm 11.6 \mathrm{~ms}$ and baseline QRS was $170 \pm 21 \mathrm{~ms}$. With selective HBP, QRS was $157 \pm 16 \mathrm{~ms}$. His bundle capture threshold was $1.7 \pm 0.7 \mathrm{~V}$ at $0.8 \pm 0.4 \mathrm{~ms}$ at baseline. With programming to standard biventricular pacing, the mean QRS improved to $141 \pm 15 \mathrm{~ms}$. The average QRS further decreased to $110 \pm 14 \mathrm{~ms}$ with sequential His bundle and left ventricular pacing (Figure $1 \mathrm{~A}$, comparing all modes $p<.0005$ ). The narrowest paced QRS with sequential His bundle and left ventricular pacing occurred at an average offset of CS pacing $42 \pm 27 \mathrm{~ms}$ after His pacing. In a majority of patients (15 of 21), this optimal offset was equal to or less than the measured $\mathrm{H}-\mathrm{V}$ interval and only in 2 was it longer than the measured $\mathrm{H}-\mathrm{V}$ interval by $10 \mathrm{~ms}$. In 17 patients, adequate electrograms were available for determination of vectorcardiographic QRS area at baseline, with biventricular pacing, and sequential His bundle and ventricular pacing. Sequential His bundle and ventricular pacing resulted in a smaller average paced QRS area of $38.5 \pm 22.6 \mu \mathrm{Vs}$ compared to biventricular pacing $67.5 \pm 24.0+\mu \mathrm{Vs}$ and at baseline $78.1 \pm 28.1 \mu \mathrm{Vs}(p<.0005$; Figure 1B).

In patients who underwent atrioventricular nodal ablation, baseline QRS was $166 \pm 19$ and $150 \pm 22$ ms with selective HBP. His bundle capture threshold was $2.2 \pm 1.6 \mathrm{~V}$. With biventricular pacing QRS was $137 \pm 16 \mathrm{~ms}$ and decreased to $109 \pm 14 \mathrm{~ms}$ with sequential HBP and left ventricular pacing $(p<.005)$. In 10 of 13 patients, adequate electrocardiograms were available for analysis of vectorcardiographic area. Sequential His bundle and left ventricular pacing resulted in a smaller average paced QRS area of $32.0 \pm 17.4 \mu \mathrm{Vs}$
TABLE 1 Baseline electrophysiologic and clinical characteristics at implant

\begin{tabular}{|lll|}
\hline Baseline characteristic & Total $(\boldsymbol{n = 2 1 )}$ & $\begin{array}{l}\text { Patients with AV nodal } \\
\text { ablation }(\boldsymbol{n}=13)\end{array}$ \\
\hline Age, mean years & $70.7 \pm 9.9$ & $69.9 \pm 10.7$ \\
\hline Female, $n$ (\%) & $7(33 \%)$ & $3(23 \%)$ \\
\hline QRS duration, mean milliseconds & $169.5 \pm 20.8$ & $166.8 \pm 19.1$ \\
\hline Left Ventricular Ejection Fraction, \% & $27.6 \pm 6.4$ & $28.1 \pm 8.0$ \\
\hline Left Ventricular End Diastolic & $172.3 \pm 78.3$ & $171.6 \pm 86.1$ \\
\hline \multicolumn{1}{|c|}{ Volume, ml } & & $8(62 \%)$ \\
\hline Left Bundle Branch Block pattern, $n$ (\%) & $12(57 \%)$ & $56.2 \pm 12.5$ \\
\hline H-V interval, mean milliseconds & $56.8 \pm 11.6$ & $7(54 \%)$ \\
\hline Nonischemic cardiomyopathy, $n$ (\%) & $12(57 \%)$ & $13(100 \%)$ \\
\hline Atrial fibrillation, $n$ (\%) & $15(71 \%)$ & $13(100 \%)$ \\
\hline Hypertension, $n$ (\%) & $19(90 \%)$ & $7(53.8 \%)$ \\
\hline Diabetes mellitus, $n$ (\%) & $10(48 \%)$ & $6(46.2 \%)$ \\
\hline Chronic kidney disease, $n$ (\%) & $9(43 \%)$ & $11(85 \%)$ \\
\hline ACE inhibitor/ARB use, $n$ (\%) & $18(82 \%)$ & $9(69 \%)$ \\
\hline Beta-blocker use, $n$ (\%) & $15(71 \%)$ & $8(62 \%)$ \\
\hline Aldosterone antagonist use, $n$ (\%) & $15(71 \%)$ & \\
\hline
\end{tabular}




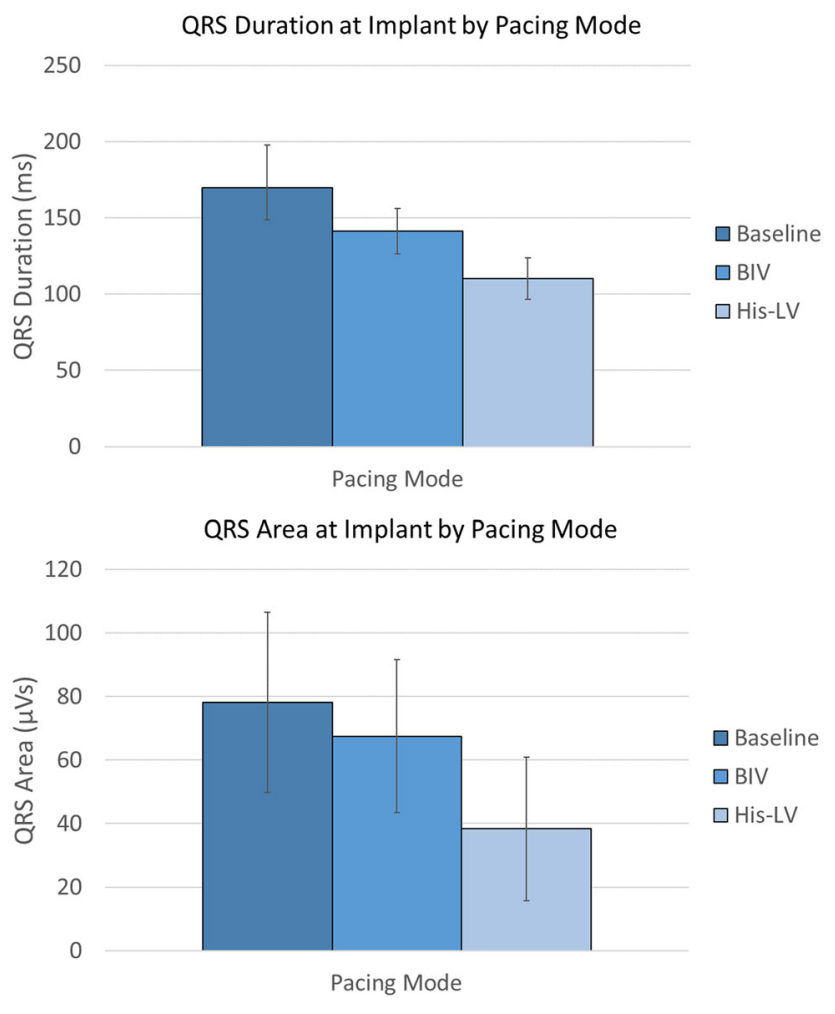

FIGURE 1 QRS duration and QRS area parameters at implant_—QRS duration (A) and QRS area (B) were decreased relative to baseline with BIV pacing and further decreased with sequential HIS-LV pacing. BIV, biventricular; HIS-LV, His and left ventricular

compared to biventricular pacing $(67.1 \pm 23.9 \mu \mathrm{Vs})$ and at baseline (69.6.1 $\pm 19.2 \mu \mathrm{Vs} ; p<.001$, Figure S3).

\subsection{Follow up}

In follow up, average $\mathrm{His}$ bundle capture thresholds rose to $3.0 \pm 2.3 \mathrm{~V}$ at $0.8 \pm 0.4 \mathrm{~ms}$ (at 29 months; range: $1.2-91.4$; median: 10.0). This was primarily seen in six patients with a rise in capture threshold greater $1.0 \mathrm{~V}$ after implant. In these patients, capture thresholds increased by an average of $3.5 \pm 1.2 \mathrm{~V}$ within the first year of follow up at a median of 102 days (average $133 \pm 112$ days). In the remaining patients, His bundle capture thresholds were stable or decreased from that at implant.

In follow up, LVEF increased from $27.6 \pm 6.4 \%$ at baseline to $41.1 \pm 12.5$ at follow up $(p=.001)$. LVEDV decreased from $172.3 \pm 78.3$ to $147.1 \pm 70.0 \mathrm{ml}$ ( $p=.0$, at 25 months; range: 0.9-97.5, median: 10.6). NYHA functional class improved from $3.1 \pm 0.5$ to $2.1 \pm 0.8(p<.001)$. Three patients were hospitalized for HF in follow up. No patients had ICD therapy or died during the follow-up period. Based on a threshold of $10 \%$ increase in LVEF or $10 \%$ reduction in LVEDV, a total of 16 of 21 patients had a structural improvement after device implant. Similarly, 14 of 21 patients had symptomatic improvement after device implant (NYHA class improvement without heart failure hospitalization or death). The frequency of either symptomatic or structural response to sequential His bundle and left ventricular pacing was not associated with baseline factors.

In the subset of patients who underwent atrioventricular nodal ablation, His bundle capture thresholds rose to $2.6 \pm 2.2 \mathrm{~V}$ with a rise of capture threshold greater that $1.0 \mathrm{~V}$ in three patients after implant. The average LVEF increased from $27.6 \pm 6.4 \%$ to $42.6 \pm 11.8 \%$ and the average LVEDV decreased from $171.6 \pm 86.1$ to $135.9 \pm 69.7 \mathrm{ml}(p<.001$ and $<.05$, respectively). In 12 patients there was structural improvement after device implant and in 11 patients NYHA class improved without heart failure hospitalization or death.

\section{4 | DISCUSSION}

In this retrospective cohort study of patients with indication for CRT in whom His pacing did not result in resynchronization, sequential His bundle and CS pacing resulted in superior electrical synchrony as determined by QRS duration and area when compared to traditional biventricular pacing. In follow up, a majority of patients had symptomatic and structural improvements in their cardiomyopathy. While this cannot be definitively attributed to CRT in the absence of a comparison arm, all patients were on maximally tolerated neurohormonal blockade before device placement.

Though biventricular pacing remains the established method of CRT, the high rate of nonresponse has prompted evaluation of HBP as a more physiologic means of inducing resynchronization. However, in the first randomized trial of an unselected population comparing His versus biventricular pacing, $48 \%$ of patients randomized to His corrective CRT crossed over to biventricular pacing due to inadequate QRS narrowing or because of high thresholds required to induce QRS narrowing. ${ }^{14}$ As shown by Uphadhyay et al., when His pacing fails to correct LBBB, proximal His-Purkinje conduction is often intact, implying that the delay in intraventricular conduction is primarily due to diffuse distal conduction or intramyocardial disease. ${ }^{22}$ Our study demonstrates that in such patients, the addition of a CS lead with fusion of His and left ventricular pacing, results in superior acute electrical resynchronization when compared to biventricular pacing.

Despite similarities in the surface electrocardiogram between right ventricular pacing and LBBB, right ventricular pacing alters ventricular activation in patients with LBBB and is associated with slower right and left ventricular activation, greater inter and intraventricular mechanical dyssynchrony, and potential shift of left ventricular activation delay away from the intended CS lead location. ${ }^{23-26}$ Therefore, even when HBP does not correct LBBB, it preserves the remaining His-Purkinje activation and results in improved resynchronization when fused with left ventricular pacing as compared with right ventricular pacing. As shown by Padeletti et al., this method of CRT also results in superior hemodynamic response over the range of atrioventricular intervals when compared to biventricular pacing. ${ }^{27}$ A similar approach to CRT is employed by adaptive left ventricular pacing algorithms which attempt to fuse left ventricular pacing with intrinsic conduction. ${ }^{28}$ This approach yields comparable reductions in QRS duration and area but these improvements are sensitive to programming of the atrioventricular offset 
from device measured intrinsic conduction. ${ }^{29}$ This is mirrored in hemodynamic studies in which the benefit of fusing biventricular pacing with intrinsic activation is sensitive to optimization of the atrioventricular delay. ${ }^{27}$ Finally, prolonged atrioventricular conduction which occurs in $15 \%-50 \%$ of patients undergoing CRT may limit the use of adaptive atrioventricular delay programming. ${ }^{30,31}$ The use of HBP has the advantage of allowing for optimization of the atrioventricular interval in patients with atrioventricular conduction disease. The improvements in acute electrical resynchronization were also seen in the subgroup of patients who underwent atrioventricular nodal ablation for $\mathrm{AF}$ in whom fusion of intrinsic activation with biventricular pacing would not be possible.

Whether more physiologic and augmented acute electrical resynchronization will result in improvement of long-term outcomes remains uncertain, however there are several lines of evidence which suggest this. In prior studies, baseline QRS duration and QRS area are associated with mechanical dyssynchrony and the response rate to conventional CRT. ${ }^{25,32-36}$ The magnitude of reduction in QRS duration with biventricular pacing has also been shown to be predictive of echocardiographic and clinical response to CRT. ${ }^{37-41}$ In studies of optimizing interventricular intervals in biventricular pacing, minimization of QRS area has been associated with improved acute hemodynamic response to CRT. ${ }^{42-44}$ The prognostic significance QRS area reduction has not been evaluated, however as QRS area is a function of QRS duration and amplitude, it is plausible that reduction in QRS area with CRT is also predictive of long-term response.

This study complements the findings of two prior studies describing fusion of HBP with left ventricular pacing. Vijayaraman et al. described His-Optimized CRT in 27 patients in whom His pacing resulted in partial QRS narrowing without complete reversal. These patients likely had less extensive conduction system disease than the current cohort given partial QRS narrowing with HBP. ${ }^{45}$ Boczar et al. described fusion of HBP with biventricular or left ventricular pacing in 10 of 14 patients with permanent atrial fibrillation and bundle branch block referred for CRT. This population was more similar to the current cohort as only 2 of 14 patients had significant QRS narrowing with HBP alone and a majority had nonischemic cardiomyopathy. Unlike the present study, a high degree of HBP was achieved ( $290 \%$ in all) without the use of atrioventricular nodal ablation. In addition, in a majority of cases of left bundle branch, the narrowest paced QRS was obtained via fusion of HBP with biventricular rather than left ventricular pacing. The current study did not examine this configuration, however, it may suggest prolonged right bundle branch conduction in the patients studied by Boczar et al. ${ }^{15}$ Similar to this study, a majority of patients in the reports by Vijayaraman and Boczar et al. demonstrated improvement in echocardiographic and clinical parameters in follow up. ${ }^{15,45}$

\section{5 | STUDY LIMITATIONS}

The present study is limited given its retrospective observational nature in nonconsecutive patients. The examined cohort represents approximately $8 \%$ of patients undergoing CRT at our institution and may not be representative of the general population of patients receiving CRT. In addition, the success rate of achieving noncorrective HBP with acceptable thresholds in patients with indications for CRT cannot be assessed due to incomplete information regarding attempted but abandoned HBP. We estimate a 70\% success rate for selective HBP in patients with atrioventricular or infra-Hisian conduction disease at our institution. Improvements in ejection fraction and clinical status cannot be definitively attributed to CRT in this study. We were not able review medication adjustments after implantation extensively for all patients and this may instead have impacted changes in ejection faction. A comparison between sequential $\mathrm{His}$ bundle and left ventricular pacing and biventricular pacing was only performed at implant. Advances in biventricular pacing such as multipoint pacing or adaptive atrioventricular delays may also decrease the difference between the described approach and biventricular pacing. Finally, the higher HBP thresholds obtained imply a reduced battery life when compared with those typically obtained with biventricular pacing. Consequently, the long-term advantage of this approach to CRT including the tradeoff between improved electrical resynchronization and battery life requires further study in a prospective manner.

\section{6 | CONCLUSIONS}

In summary, sequential His bundle and left ventricular pacing results in superior acute electrical synchrony in patients with indication for CRT when selective His pacing does not correct the QRS. In follow up echocardiographic parameters and functional status improved after device implant in our cohort. Given the advanced conduction disease in this population, His pacing thresholds may rise significantly in a minority of patients. Prospective studies are warranted to compare the relative long-term efficacy of this method for CRT in comparison with biventricular pacing and other emerging methods for more physiologic resynchronization. An important consideration should include the potential tradeoff between improved electrical resynchronization and potential reductions in battery life.

\section{ORCID}

Amrish Deshmukh (D) http://orcid.org/0000-0002-2733-2844

\section{REFERENCES}

1. Baldasseroni S, Gentile A, Gorini M, et al. Intraventricular conduction defects in patients with congestive heart failure: left but not right bundle branch block is an independent predictor of prognosis. a report from the Italian Network on Congestive Heart Failure (IN-CHF database). Ital Heart J. 2003;4(9):607-613.

2. Kearney MT, Zaman A, Eckberg DL, et al. Cardiac size, autonomic function, and 5-year follow-up of chronic heart failure patients with severe prolongation of ventricular activation. J Card Fail. 2003;9(2): 93-99.

3. Bader H, Garrigue S, Lafitte S, et al. Intra-left ventricular electromechanical asynchrony. A new independent predictor of severe cardiac events in heart failure patients. J Am Coll Cardiol. 2004; 43(2):248-256 
4. Moss AJ, Hall WJ, Cannom DS, et al. Cardiac-resynchronization therapy for the prevention of heart-failure events. N Engl J Med. 2009;361(14):1329-1338.

5. van Gelder BM, Scheffer MG, Meijer A, Bracke FA. Transseptal endocardial left ventricular pacing: an alternative technique for coronary sinus lead placement in cardiac resynchronization therapy. Hear Rhythm. 2007;4(4):454-460.

6. Ploux $S$, Strik $M$, van Hunnik $A$, van Middendorp $L$, Kuiper $M$, Prinzen FW. Acute electrical and hemodynamic effects of multisite left ventricular pacing for cardiac resynchronization therapy in the dyssynchronous canine heart. Hear Rhythm. 2014;11(1):119-125.

7. Reddy VY, Miller MA, Neuzil P, et al. Cardiac resynchronization therapy with wireless left ventricular endocardial pacing. J Am Coll Cardiol. 2017;69(17):2119-2129.

8. Lustgarten DL, Crespo EM, Arkhipova-Jenkins I, et al. His-bundle pacing versus biventricular pacing in cardiac resynchronization therapy patients: a crossover design comparison. Hear Rhythm. 2015;12(7):1548-1557.

9. Ajijola OA, Upadhyay GA, Macias C, Shivkumar K, Tung R. Permanent His-bundle pacing for cardiac resynchronization therapy: initial feasibility study in lieu of left ventricular lead. Hear Rhythm. 2017; 14(9):1353-1361.

10. Sharma PS, Dandamudi G, Herweg B, et al. Permanent His-bundle pacing as an alternative to biventricular pacing for cardiac resynchronization therapy: a multicenter experience. Hear Rhythm. 2018;15(3):413-420.

11. Meng DF, Sun R, Peng LX, et al. Long-term outcomes of His bundle pacing in patients with heart failure with left bundle branch block. Heart. 2018;9:92-99.

12. Sharma PS, Naperkowski A, Bauch TD, et al. Permanent His bundle pacing for cardiac resynchronization therapy in patients with heart failure and right bundle branch block. Circ Arrhythmia Electrophysiol. 2018;11:9

13. Arnold AD, Shun-Shin MJ, Keene D, et al. His resynchronization versus biventricular pacing in patients with heart failure and left bundle branch block. J Am Coll Cardiol. 2018;72(24):3112-3122.

14. Upadhyay GA, Vijayaraman P, Nayak HM, et al. His corrective pacing or biventricular pacing for cardiac resynchronization in heart failure. J Am Coll Cardiol. 2019;74(1):157-159.

15. Boczar K, Sławuta A, Ząbek A, et al. Cardiac resynchronization therapy with His bundle pacing. Pacing Clin Electrophysiol. 2019; 42(3):374-380.

16. Strik $M$, van Middendorp LB, Houthuizen $P$, et al. Interplay of electrical wavefronts as determinant of the response to cardiac resynchronization therapy in dyssynchronous canine hearts. Circ Arrhythmia Electrophysiol. 2013;6(5):924-931.

17. Padeletti L, Pieragnoli P, Ricciardi G, et al. Simultaneous His bundle and left ventricular pacing for optimal cardiac resynchronization therapy delivery: acute hemodynamic assessment by pressurevolume loops. Circ Arrhythm Electrophysiol. 2016;9:5.

18. Surawicz B, Childers R, Deal BJ, Gettes LS. SAHA/ACCF/HRS Recommendations for the Standardization and Interpretation of the Electrocardiogram Part III: Intraventricular Conduction Disturbances A Scientific Statement From the American Heart Association Electrocardiography and Arrhythmias Committee, Council on Clinical Cardiology; the American College of Cardiology Foundation; and the Heart Rhythm Society Endorsed by the International Society for Computerized Electrocardiology. 2009

19. Deshmukh P, Casavant DA, Romanyshyn M, Anderson K. Permanent, direct His-bundle pacing: a novel approach to cardiac pacing in patients with normal His-purkinje activation. Circulation. 2000; 101(8):869-877.

20. Vijayaraman P, Dandamudi G, Zanon F, et al. Permanent His bundle pacing: recommendations from a multicenter $\mathrm{His}$ bundle pacing collaborative working group for standardization of definitions, implant measurements, and follow-up. Hear Rhythm. 2018;15(3): 460-468.

21. Engels EB, Végh EM, Vandeursen CJM, Vernooy K, Singh JP, Prinzen FW. T-wave area predicts response to cardiac resynchronization therapy in patients with left bundle branch block. J Cardiovasc Electrophysiol. 2015;26(2):176-183.

22. Upadhyay GA, Cherian T, Shatz DY, et al. Intracardiac delineation of septal conduction in left bundle branch block patterns: mechanistic evidence of left intra-hisian block circumvented by His pacing. Circulation. 2019.

23. Varma N. Left ventricular electrical activation during right ventricular pacing in heart failure patients with LBBB: visualization by electrocardiographic imaging and implications for cardiac resynchronization therapy. J Electrocardiol. 2015;48(1):53-61.

24. Eschalier R, Ploux S, Lumens J, et al. Detailed analysis of ventricular activation sequences during right ventricular apical pacing and left bundle branch block and the potential implications for cardiac resynchronization therapy. Hear Rhythm. 2015;12(1):137-143.

25. Mafi Rad M, Blaauw Y, Dinh T, et al. Different regions of latest electrical activation during left bundle-branch block and right ventricular pacing in cardiac resynchronization therapy patients determined by coronary venous electro-anatomic mapping. Eur J Heart Fail. 2014;16(11):1214-1222.

26. Ludwig DR, Tanaka H, Friehling M, Gorcsan J, Schwartzman D. Further deterioration of LV ejection fraction and mechanical synchrony during RV apical pacing in patients with heart failure and LBBB. J Cardiovasc Transl Res. 2013;6(3):425-429.

27. Padeletti L, Pieragnoli P, Ricciardi G, et al. Simultaneous His bundle and left ventricular pacing for optimal cardiac resynchronization therapy delivery. Circ Arrhythmia Electrophysiol. 2016;9:5.

28. Martin DO, Lemke B, Birnie D, et al. Investigation of a novel algorithm for synchronized left-ventricular pacing and ambulatory optimization of cardiac resynchronization therapy: Results of the adaptive CRT trial. Hear Rhythm. 2012;9(11):1807-1814.

29. Engels EB, Thibault B, Mangual J, et al. Dynamic atrioventricular delay programming improves ventricular electrical synchronization as evaluated by 3D vectorcardiography. J Electrocardiol. 2020;58: 1-6.

30. Friedman DJ, Bao H, Spatz ES, Curtis JP, Daubert JP, Al-Khatib SM. Association between a prolonged PR interval and outcomes of cardiac resynchronization therapy. Circulation. 2016;134(21): 1617-1628.

31. Olshansky B, Day JD, Sullivan RM, Yong P, Galle E, Steinberg JS. Does cardiac resynchronization therapy provide unrecognized benefit in patients with prolonged PR intervals? The impact of restoring atrioventricular synchrony: an analysis from the COMPANION Trial. Hear Rhythm. 2012;9(1):34-39.

32. Oyenuga $\mathrm{O}$, Hara $\mathrm{H}$, Tanaka $\mathrm{H}$, et al. Usefulness of echocardiographic dyssynchrony in patients with borderline qrs duration to assist with selection for cardiac resynchronization therapy. JACC Cardiovasc Imaging. 2010;3(2):132-140.

33. Gold MR, Thébault C, Linde $C$, et al. Effect of QRS duration and morphology on cardiac resynchronization therapy outcomes in mild heart failure. Circulation. 2012;126(7):822-829.

34. Sipahi I, Carrigan TP, Rowland DY, Stambler BS, Fang JC. Impact of QRS duration on clinical event reduction with cardiac resynchronization therapy. Arch Intern Med. 2011;171(16):1454-1462.

35. Emerek K, Friedman DJ, Sørensen PL, et al. Vectorcardiographic QRS area is associated with long-term outcome after cardiac resynchronization therapy. Hear Rhythm. 2019;16(2):213-219.

36. van Stipdonk AMW, ter Horst I, Kloosterman M, et al. QRS area is a strong determinant of outcome in cardiac resynchronization therapy. Circ Arrhythmia Electrophysiol. 2018;11:12.

37. Lecoq G, Leclercq C, Leray E, et al. Clinical and electrocardiographic predictors of a positive response to cardiac resynchronization 
therapy in advanced heart failure. Eur Heart J. 2005;26(11) 1094-1100.

38. Rickard J, Popovic Z, Verhaert D, et al. The QRS narrowing index predicts reverse left ventricular remodeling following cardiac resynchronization therapy. Pacing Clin Electrophysiol. 2011;34(5):604-611.

39. Rickard J, Cheng A, Spragg D, et al. QRS narrowing is associated with reverse remodeling in patients with chronic right ventricular pacing upgraded to cardiac resynchronization therapy. Hear Rhythm. 2013;10(1):55-60.

40. Hsing JM, Selzman KA, Leclercq C, et al. Paced left ventricular QRS width and ECG parameters predict outcomes after cardiac resynchronization therapy. Circ Arrhythmia Electrophysiol. 2011;4(6): 851-857.

41. Trucco E, Tolosana JM, Arbelo E, et al. Improvement of reverse remodeling using electrocardiogram fusion-optimized intervals in cardiac resynchronization therapy. JACC Clin Electrophysiol. 2018; 4(2):181 LP-181189.

42. van Deursen CJ, Wecke L, van Everdingen WM, et al. Vectorcardiography for optimization of stimulation intervals in cardiac resynchronization therapy. J Cardiovasc Transl Res. 2015;8(2):128-137.

43. De Pooter J, El Haddad M, De Buyzere M, et al. Biventricular paced QRS area predicts acute hemodynamic CRT response better than QRS duration or QRS amplitudes. J Cardiovasc Electrophysiol. 2017; 28(2):192-200.
44. Ross S, Odland $\mathrm{HH}$, Aranda A, et al. Cardiac resynchronization therapy when no lateral pacing option exists: vectorcardiographic guided non-lateral left ventricular lead placement predicts acute hemodynamic response. EP Eur. 2018;20(8): 1294-1302.

45. Vijayaraman P, Herweg B, Ellenbogen KA, Gajek J. His-optimized cardiac resynchronization therapy to maximize electrical resynchronization. Circ Arrhythmia Electrophysiol. 2019;12(2):e006934.

\section{SUPPORTING INFORMATION}

Additional Supporting Information may be found online in the supporting information tab for this article.

How to cite this article: Deshmukh A, Sattur S, Bechtol T, Heckman LIB, Prinzen FW, Deshmukh P. Sequential His bundle and left ventricular pacing for cardiac resynchronization. J Cardiovasc Electrophysiol. 2020;31: 2448-2454. https://doi.org/10.1111/jce.14674 